\title{
Gregarious Settlement by the Larvae of Hydroides dianthus (Polychaeta: Serpulidae)*
}

\author{
R. S. Scheltema, I. P. Williams, M. A. Shaw and C. Loudon \\ Woods Hole Oceanographic Institution, Woods Hole, Massachusetts 02543, USA
}

\begin{abstract}
Larval development of the serpulid polychaete worm, Hydroides dianthus Verrill 1893 parallels that of other closely related species. The larvae prefer to settle upon surfaces already inhabited by other members of their own species rather than to colonize surfaces without such conspecific residents. However, very wide variations in the intensity of settlement are observed. These differences in the amount of settlement cannot presently be attributed to any single variable. Gregarious settlement appears to be typical for sessile species which do not have the ability to reproduce asexually after settlement.
\end{abstract}

\section{INTRODUCTION}

Gregariousness may be defined as the interactions between planktonic larvae and attached resident members of their own species that result in settlement and metamorphosis of the larvae. Intra-specific settlement responses are now well known for a number of invertebrate taxa. For example, it has been shown that cyprids of the barnacles Elminius modestus and Balanus balanoides settle gregariously in response to members of their own species (Knight-Jones and Stephenson, 1950; Knight-Jones, 1953), and veligers of oysters belonging to Ostrea edulis and Crassostrea virginica also settle in response to attached members of their own kind (Knight-Jones, 1951; Crisp, 1967; Bayne, 1969; Hidu, 1969). At least one serpulid polychaete (sensu stricto), namely Pomatoleios kraussi from the Arabian Gulf, probably also settles gregariously (Crisp, 1977). Biological literature on gregarious settlement of other marine species has been summarized by Crisp (1974) and Scheltema (1974).

The present account describes a gregarious settlement response heretofore unknown in the sessile serpulid tube-worm Hydroides dianthus. This species secretes a calcareous tube upon submerged marine surfaces and is a key species in certain faunal assemblages (Haines and Maurer, 1980). The experiments

\footnotetext{
- Contribution No. 4785, Woods Hole Oceanographic Institution
}

that show gregariousness in Hydroides dianthus were conducted by using larvae grown in the laboratory.

\section{CULTURE METHODS}

Sexually mature individuals attached to small cobbles were dredged during mid-June from a single population off Nobska Point, Vineyard Sound, Massachusetts. Eggs obtained from ripe females were artificially fertilized in finger bowls. The young trochophores were transferred 12-15 h after fertilization to larger 3-1 jars of filtered sea water, gently aerated, and fed unicellular algae from cultures of Dunaliella tertiolecta and Thalassiosira pseudonana at a ratio of $1: 1$. The initial total concentration was $10^{5}$ cells $\mathrm{ml}^{-1}$. Inoculum for the unialgal cultures was kindly provided by Dr. R. R. Guillard. In some instances Isochrysis galbana was also used in a mixture of $2: 1: 1 T$. pseudonana, D. tertiolecta and I. galbana respectively. Every second day the larvae were transferred to fresh filtered sea water by passing the entire culture through a fine-meshed $35-\mu \mathrm{m}$ sieve constructed from Nytex cloth attached to one end of a 3-cm length of polyvinyl chloride pipe $7 \mathrm{~cm}$ in diameter. The surface of the screen was kept submerged during the transfer to prevent damage to the trochophore larvae. After the water was changed, sufficient new algal culture was added to bring the concentration to $10^{5}$ cells $\mathrm{ml}^{-1}$. The time required for completion develop- 
ment to the settlement stage varied with both water temperature and the species of algae used. Except for the first few, all cultures were grown in a constanttemperature cabinet at $24^{\circ} \mathrm{C}$.

\section{DESCRIPTION OF LARVAE}

The complete larval development of Hydroides dianthus Verrill, 1893 has not yet been described; it closely parallels that of the related species Hydroides norvegica portrayed by Wisely (1958). After fertilization, development proceeds by means of spiral cleavage to a typical trochophore stage. At $18 \mathrm{~h}$ this trochophore larva (Fig. la) is already actively swimming and has a prototroch (pr) which divides it into an episphere (ep) with an apical tuft (at) and a vaculated hyposphere (hy). The larva is about $60-70 \mu \mathrm{m}$ in diameter at the prototroch, and $85 \mu \mathrm{m}$ in length from apical tuft to the apex of the hyposphere. The length of the apical tuft is $55-60 \mu \mathrm{m}$. At the end of $1.5 \mathrm{~d}$ a gut (oe, st, it) has formed and the larva is now feeding (Fig. lb). In addition to the prototroch a second ciliary band, the metatroch (mt) has formed. The mouth $(\mathrm{m})$ opens between the two bands of cilia, the anus (an) at base of the hyposphere. There is a single red eye spot (is); as development progresses a second eye spot forms on the opposite side. After about 5 d at $25^{\circ} \mathrm{C}$ development has progressed to the settlement stage (Fig. 1c). The larva now has 3 setigerous segments (ch-1, ch-2, ch-3), 2 setae extending from each setal sac (cs). There are also uncini (un) on the second and third segments, and a third set on what presumably will become the fourth segment. Terminally, there is an anal vacuole (av); anterior to this vacuole the anus (an) opens dorsally. Two bands of red pigment spots are evident associated with the anterior ciliary bands. The morphological and behavioral changes at settlement have been described in related forms by Segrove (1941) and Wisely (1958); they do not appear to differ significantly in Hydroides dianthus. At metamorphosis there is a transformation in which the prototroch and metatroch are lost; the larva sticks to the substratum and is no longer able to swim. Branchial rudiments appear (Fig. 2) and subsequently a tube is formed. The description here is only very brief because there are no substantive differences in the development of Hydroides dianthus and other related species that have already been well described elsewhere (Segrove, 1941).
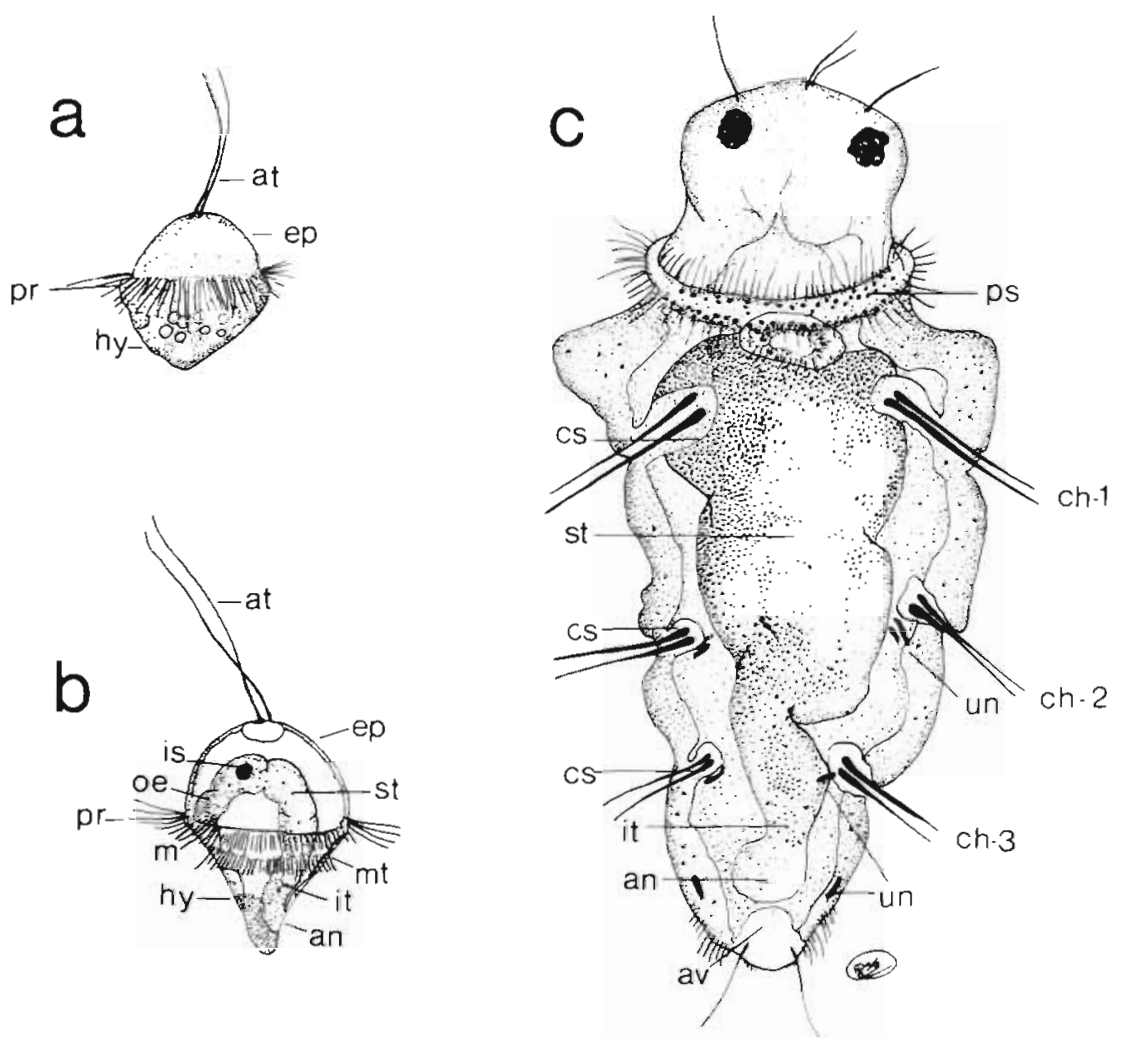

Fig. 1. Hydroides dianthus. Developmental stages. (a) Early trochophore larvae after $18 h_{;}$(b) trochophore $1 \% / 2$ d after fertilization; digestive system is complete and has become functional; (c) 5-d larva which has reached the morphological stage at which settlement has become possible. an: anus; at: apical tuft; av: anal vesical; Ch-1, Ch-2, Ch-3: first, second and third pair of setae respectively; es: setal sac; ep: episphere; hy: hyposphere; is: single red eye spot, a second one develops later; it: intestine; $m$ : mouth; mt: metatroch; oe: oesophagus; pr: prototroch; ps: bands of red pigments spots; st: stomach; un: uncini 


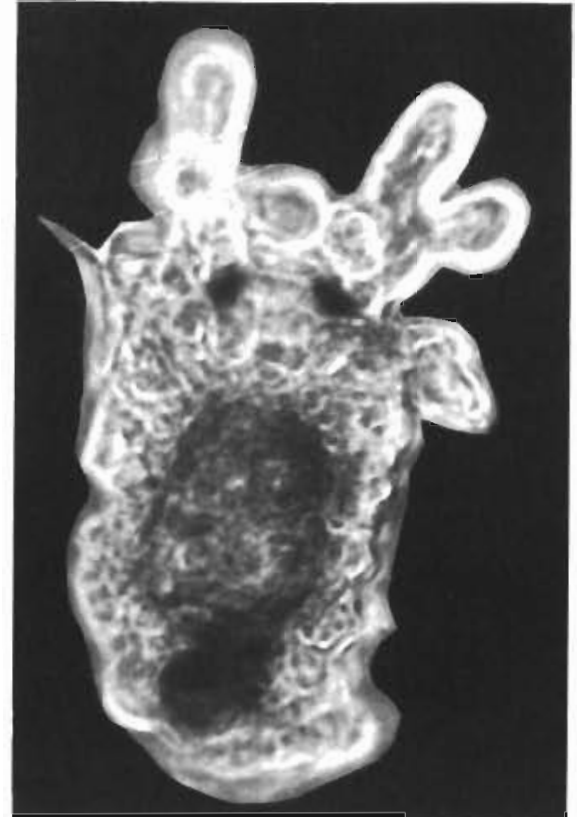

Fig. 2 Hydroides dianthus. Settled larva. Metamorphosis has begun and a rudimentary branchial crown has formed

\section{EXPERIMENTAL METHODS}

The experiments to demonstrate gregarious settlement were conducted in large clean finger bowls, 19 $\mathrm{cm}$ in diameter, containing approximately $0.8 \mathrm{l}$ sea water. The larvae were presented with a control surface - a $1.5 \times 1.5 \mathrm{~cm}$ slate, left in a running seawater table for 2 days or more until it had acquired a microbial film - and an experimental surface - a slate of similar size to which were attached resident individuals of Hydroides dianthus. The slates were then placed on the bottom of the finger bowl, and larvae competent to settle were introduced. The concentration was such that there always remained an excess of larvae for the duration of the experiment. The finger bowls were placed in an evenly lighted culture cabinet, and pairs of control and experimental slates were placed in such a way that the results would not be affected by a bias related to their position in the bowls. No consistent differences were in fact observed between the pairs of slates from opposite sides of the bowls. No settlement occurred on the glass surfaces of the finger bowls during the course of the experiments because they were cleaned at the beginning of the experiment and had not acquired a suitable microbial film. In a few experiments slates of $3.0 \times 1.5 \mathrm{~cm}$ or glass slides of either $3.8 \times 2.5 \mathrm{~cm}$ or $2.0 \times 2.5 \mathrm{~cm}$ were used. The results of the experiments were recorded by drawing the distributions both of settled larvae (Fig. 3) and of resident species on squared paper by means of a camera lucida on a binocular stereomicroscope (Wild M-5) at $25 \mathrm{X}$. This method provided a permanent record for later analysis.

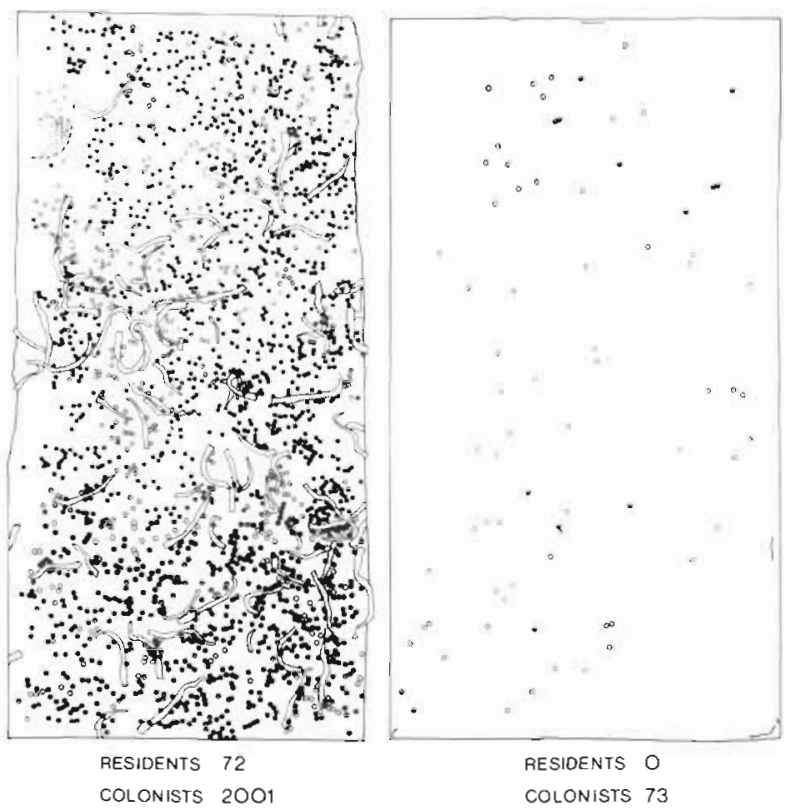

Fig. 3 Hydroides dianthus. Settlement of larvae on slates $3.0 \times 1.5 \mathrm{~cm}$; each dot indicates a newly settled individual. Larvae were given a choice of two surfaces. Right: Filmed surface without resident individuals of $H$. dianthus; settlement is sparse and occurred only after $12 \mathrm{~h}$. Le f $\mathrm{t}$ : Surface with 72 resident individuals as shown by outlines of tubes; settlement is heavy, more than 20 times that on the right and most settlement occurred within the first $8 \mathrm{~h}$. Filled circles: Larvae settled within the first $8 \mathrm{~h}$; open circles: larvae settled between the 8 th and 13 th $\mathrm{h}$ of experiment; half filled circles: larvae settled between 13 and $18 \mathrm{~h}$ after beginning of experiment. Distribution was recorded on squared paper using a camera lucida on a stereo-microscope at $25 \mathrm{X}$ 


\section{RESULTS}

The outcome of the experiments were quickly apparent and in most instances quite striking; an example is shown in Figure 3 . Here the right-hand rectangle represents a $3.0 \times 1.5 \mathrm{~cm}$ control slate on which $73 \mathrm{Hy}$ droides dianthus larvae had settled after exposure for $18 \mathrm{~h}$. Each newly settled individual is represented by a small circle. On the left is an experimental slate of the same dimensions initially populated, as indicated by the tubes, by 72 residents of $H$. dianthus; here 2001 colonizing larvae settled during the same time interval. Clearly, when given a choice most colonizers selected the slate on the left. Of 2074 colonizers, $96.4 \%$ preferred to settle near resident members of their own species; only $3.6 \%$ settled on the control slate. This result is further supported by 49 additional experiments summarized in Figure 4. Here the horizontal axis shows intervals indicating the percentage of total settlement (for each experiment) that occurred on the slates having resident individuals; the height of

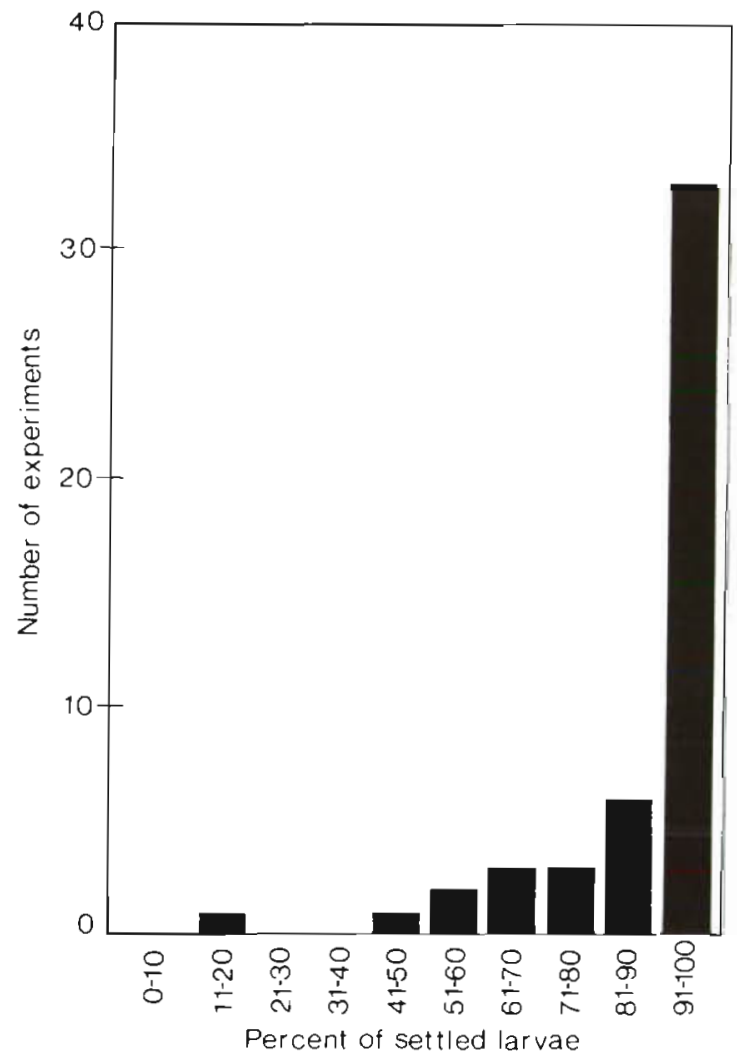

Fig. 4. Hydroides dianthus. Distribution of results from 49 experiments showing percentages of the total number in each experiment that settled on slates or glass slides having resident members of their own species. Included are 34 experiments using $1.5 \times 1.5 \mathrm{~cm}$ slates, 6 experiments using $3.8 \times 2.5 \mathrm{~cm}$ glass slides. Horizontal axis shows percent of total larvae settling on resident slide; vertical axis: number of experiments (see also Table 1) the bars shows the number of experiments in which the indicated percentage of settlement occurred. In approximately $2 / 3$ of all experiments, more than $90 \%$ of the colonizing larvae settled on slates or slides with resident individuals of their own species rather than on the controls, and in only two instances did less than half of the colonizers settle on slates with resident $H$. dianthus.

The non-parametric Mann-Whitney U test utilizing data from 34 experiments and values for the $\mathrm{n} u \mathrm{~m}$ b e r (rather than percentage) of larvae that settled shows a highly significant difference $(\mathrm{P}<0.001)$ between experimental and control slates. Only data from slates of similar size, namely $1.5 \times 1.5 \mathrm{~cm}$, were used and are tabulated (Table 1).

There are large differences - up to 40 -fold - in the intensity of larval settlement between experiments concealed by treating the data as in Figure 4. These differences (indicated in Table 1) may be attributed to a number of possible variables which include: (1) the number of attached resident Hydroides dianthus on the experimental slates; (2) the number of $H$. dianthus larvae available for settlement; (3) the age of the resident $H$. dianthus on experimental slates: (4) differences in the state of development of $H$. dianthus larvae, or - more precisely - the time elapsed since larvae

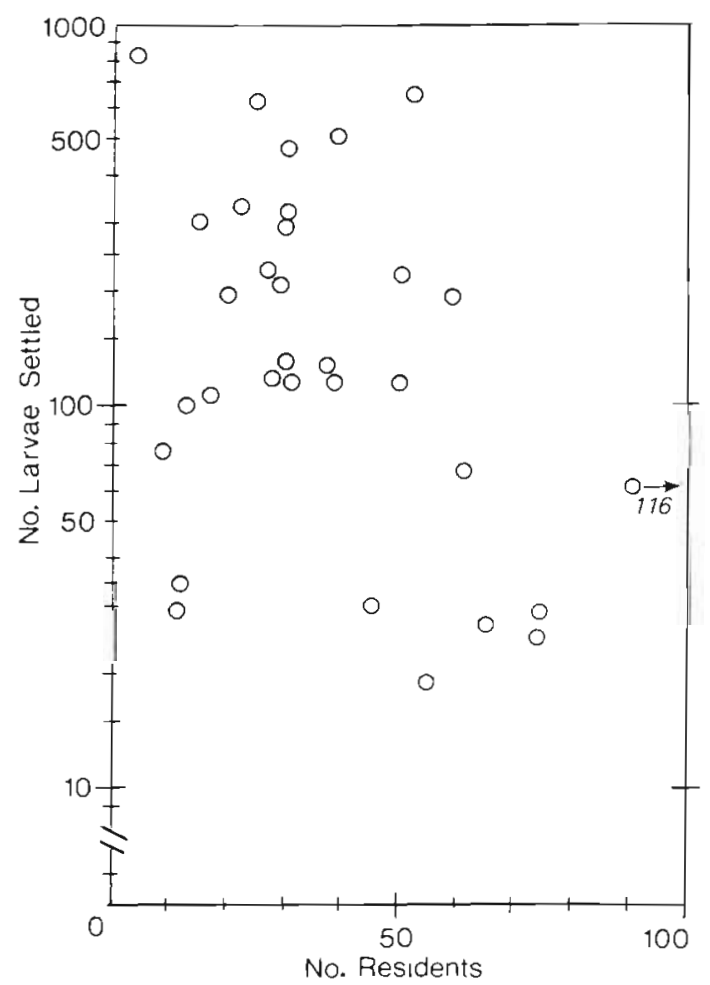

Fig. 5. Hydroides dianthus. Numbers of larvae settling in relation to the number of residents on $1.5 \times 1.5 \mathrm{~cm}$ slates. Data are from Table 1. A single point has been omitted - viz. settlement of 204 larvae on slate with 133 residents of Hydroides dianthus 
Table 1. Hydroides dianthus. Numbers of larvae settling gregariously on $1.5 \times 1.5 \mathrm{~cm}$ slates with and without resident members of their own species

\begin{tabular}{|c|c|c|c|c|}
\hline $\begin{array}{c}\text { A } \\
\text { Slates with resident } \\
\text { individuals }\end{array}$ & $\begin{array}{c}\text { B } \\
\text { Control slates }\end{array}$ & $\begin{array}{c}C \\
\operatorname{Total}(A+B)\end{array}$ & $\begin{array}{c}\mathrm{D} \\
\text { Percent of total } \\
\text { on resident slates } \\
(\mathrm{A} / \mathrm{C} \times 100)\end{array}$ & $\begin{array}{c}\mathrm{E} \\
\text { No. of resident } \\
\text { individuals }\end{array}$ \\
\hline 818 & 4 & 822 & 99.5 & 4 \\
\hline 647 & 20 & 667 & 97.0 & 52 \\
\hline 633 & 156 & 789 & 80.2 & 25 \\
\hline 510 & 125 & 635 & 80.3 & 39 \\
\hline 466 & 39 & 505 & 92.3 & 30 \\
\hline 368 & 25 & 393 & 93.6 & 12 \\
\hline 343 & 1 & 344 & 99.7 & 127 \\
\hline 340 & 15 & 355 & 95.8 & 30 \\
\hline 306 & 25 & 331 & 92.4 & 15 \\
\hline 300 & 4 & 304 & 98.6 & 30 \\
\hline 274 & 125 & 399 & 68.7 & 27 \\
\hline 221 & 1 & 222 & 99.5 & 50 \\
\hline 206 & 0 & 206 & 100.0 & 29 \\
\hline 204 & 0 & 204 & 100.0 & 133 \\
\hline 196 & 1 & 197 & 99.4 & 59 \\
\hline 186 & 156 & 342 & 54.4 & 20 \\
\hline 160 & 11 & 171 & 93.6 & 15 \\
\hline 155 & 16 & 171 & 90.6 & 37 \\
\hline 135 & 2 & 137 & 98.5 & 28 \\
\hline 135 & 0 & 135 & 100.0 & 52 \\
\hline 133 & 0 & 133 & 100.0 & 31 \\
\hline 133 & 5 & 138 & 96.4 & 39 \\
\hline 115 & 53 & 168 & 68.5 & 17 \\
\hline 102 & 37 & 139 & 73.4 & 13 \\
\hline 76 & 4 & 80 & 95.0 & 9 \\
\hline 68 & 0 & 68 & 100.0 & 61 \\
\hline 63 & 0 & 63 & 100.0 & 116 \\
\hline 38 & 5 & 43 & 88.3 & 12 \\
\hline 30 & 0 & 30 & 100.0 & 45 \\
\hline 29 & 0 & 29 & 100.0 & 74 \\
\hline 29 & 4 & 33 & 87.9 & 11 \\
\hline 27 & 0 & 27 & 100.0 & 65 \\
\hline 25 & 0 & 25 & 100.0 & 74 \\
\hline 19 & 0 & 19 & 100.0 & 55 \\
\hline
\end{tabular}

became physiologically competent to settle; and (5) qualitative differences in slime film on the panels.

Surprisingly, an examination of the data shows no striking relationship between the number of resident individuals and settlement of larvae (Fig. 5), at least not within the range of the resident population size used in our experiments. Inspection reveals no sig. nificant correlation between number of larvae on the vertical axis and residents in the horizontal axis ( $r=-0.17$, not significant by analysis of variance). Because Hydroides dianthus larvae were always in excess in all experiments, it seems unlikely that their numbers affected the settlement intensity, although there is no direct evidence to support this contention. A test for an analysis of variance shows no relationship between settlement intensity and age of residents. Although there were differences in the mean settlement between experiments using larvae of $4,5,6$, and 7 d (measured from time of fertilization) there appeared to be no trend in the data, and older larvae did not consistently settle more readily than younger ones as might be expected. The variable most difficult to assess is qualitative differences in the microbial slime film affecting larval settlement. We know of no way to control readily the composition of such films.

\section{DISCUSSION}

Two adaptations allow sessile marine forms to colonize successfully and rapidly the surfaces of hard substrata. On the one hand there are those species which, after settlement, rapidly reproduce asexually to form colonies that can completely pre-empt all available surface; examples are ascidians such as Botryllus schlosseri and the cheilostomatous bryozoan Schizoporella errata. On the other hand there are those forms that do not reproduce asexually after attachment; instead such species settle together in very large 
numbers, forming dense populations that arise from a gregarious response of the larvae (vide Jackson, 1977. p. 750; his Table 3). Known examples are barnacles such as Balanus balanoides and oysters such as Crassostrea virginica. Colonial species tend to have lecithotrophic larvae with a short non-feeding planktonic existence; if the species can readily overgrow other forms, only a few larvae need to settle successfully in order for such species to become established. Solitary species that have a gregarious settlement-response must produce large numbers of larvae in order to be numerous enough to settle together to form aggregations. Such species tend to have planktotrophic larvae that have a planktonic life 1 to 3 weeks; their establishment on a surface depends on massive colonization by large numbers of larvae. To this latter group of gregariously settling species may now be added the serpulid Hydroides dianthus.

Acknowledgements. This research was supported by the US Office of Naval Research, Contract No. N00014-79-C-0071 NR083-004 and by a grant from the US National Science Foundation EAR-7926381 to the first author. M. A. Shaw and C. Loudon wish to acknowledge support by Woods Hole Oceanographic Institution summer fellowships. We thank A. H. Scheltema for critically reading the manuscript.

\section{LITERATURE CITED}

Bayne, B. L. (1969). The gregarious behaviour of the larvae of Ostrea edulis L. at settlement. J. mar. biol. Ass. U. K. 49; $327-356$

This paper was presented by Dr. R. Scheltema; it was accepted for printing on January 20, 1981
Crisp, D. J. (1961). Territorial behaviour in barnacle settle. ment. J. exp. Biol. 39: 429-446

Crisp, D. J. (1967). Chemical factors inducing settlement in Crassostrea virginica (Gmelin). J. animal Ecol. 36: 329336

Crisp, D. J. (1974). Factors infiuencing the settlement of marine invertebrate larvae. In: Grant, P. T., Mackie, A. N. (eds) Chemoreception in marine organisms. Academic Press, New York, pp. 177-265

Crisp, M. (1977). The development of the serpulid Pomatoleios kraussii (Annelida, Polychaeta). J. Zool., Lond. 183: 147-160

Haines, J. L., Maurer, D. (1980) Quantitative faunal associates of the serpulid polychaetes Hydroides dianthus. Mar. Biol. 56: $43-47$

Hidu, H. (1969). Gregarious setting in the American oyster Crassostrea virginica Gmelin. Chesapeake Sci. 10: 85-92

Jackson, J. B. C. (1977). Competition on marine hard substrata: The adaptive significances of solitary and colonial strategies. Am. Nat. 111: 743-767

Knight-Jones, E. W., Stephenson, J. P. (1950) Gregariousness in the barnacle Elminius modestus Darwin. J. mar. biol. Ass. U. K. 29: 281-297

Knight-Jones, E. W. (1951). Aspects of the setting behaviour of larvae of Ostrea edulis on the Essex oyster beds. Rapp. P.-v. Réun. Cons. int. Explor. Mer 128: 30-34

Knight-Jones, E. W. (1953). Laboratory experiments on gregariousness during setting in Balanus balanoides and other barnacles. J. exp. Biol. 30: 584-598

Scheltema, R. S. (1974). Biological interactions determining larval settlement of marine invertebrates. Thalassia jugosl. 10: 263-296

Segrove, F. (1941). The development of the serpulid Pomatoceros triqueter L. Q. Jl microsc. Sci. 82: 468-540

Wisely, B. (1958). The development and settling of a serpulid worm, Hydroides norvegica Gunnerus (Polychaeta). Aust. J. mar. Freshw. Res. 9: 351-361

This paper was presented by Dr. R. Scheltema; it was accepted for printing on January 20, 1981 